\title{
OBITUARIES
}

Obituaries should be submitted by email to Ruth Doherty at r.doherty@nature.com.

All submitted obituaries should be 450 words maximum in length (apart from obituaries for

past presidents of the BDA where the length should be 800 words).

Content of the obituary is down to the individual author, and the approval of the family should

be given for the obituary prior to submission to the $B D J$.

\section{JEREMIAH JOSEPH MEE (JOE)}

\section{5-2016}

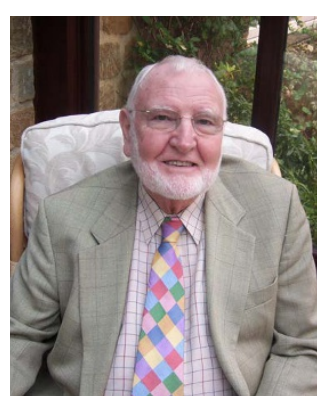

Joe Mee died on 27 April 2016 following a short illness. Joe's first career in accountancy was shortlived and to fulfil his ambition to become a dentist, he raised funds working in many diverse jobs that enabled him to study and complete his training at The Royal College of Surgeons in Ireland, qualifying in 1966. He moved to England and set up and ran several successful dental practices and was a member of his LDC playing an active role in dental politics.

Having sought treatment for alcoholism in 1981, Joe became aware that alcoholism was an issue for many of his dental colleagues and at his own expense in time and effort assisted many colleagues to find treatment for the condition. With the support of dental colleagues, the GDSC, BDA and LDC's The Sick Dentists Scheme (later the Dentists' Health Support Programme) was launched in 1986.

Joe arranged the training of recovering dental colleagues at the Department of Addictive Medicine at the University of Utah. Joe set up a national network of trained colleagues to intervene locally to help alcoholic or otherwise addicted members of the profession. This network, together with two dedicated treatment centres for health professionals, assisted dozens of colleagues to receive professional treatment and in addition arranged support for family members and practice staff. Joe was also instrumental in setting up similar programmes for The Royal Pharmaceutical Society and the Royal College of Veterinary Surgeons. In 1996, through the good offices of the BDA, Joe was awarded an MBE for his work in addiction within the professions. As
Joe wryly put it 'The Queen gave me a medal for being a drunk'.

Joe's easygoing Irish wit and charm was a good disguise for a sharp intellect and a formidable energy and drive. Joe gave short shrift to administrative panjandrums whom he thought might not share to the same extent his own enthusiasm for colleagues' welfare.

Joe's experience and expertise in the field of addiction was of immense value and so many within the profession and in the wider community owe Joe an enormous debt of gratitude.

Joe Mee was a true colossus and he leaves a unique legacy that continues to make an effective mark. Joe will be sadly missed by his immediate family together with so many whose lives were touched by his warmth, care and influence. James Willis

\section{DECLAN JOHN ANDERSON}

\section{0-2016}

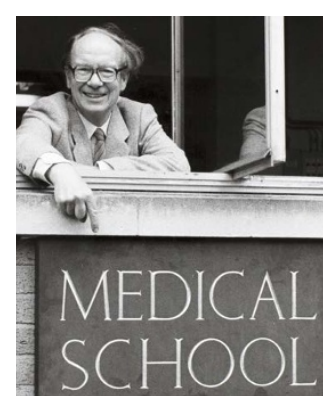

Declan Anderson was a dentist and physiologist. He died at 95 on March 272016. He was educated at Christ's Hospital School and Guy's Hospital. After graduating in dentistry

in 1942, he went on to obtain a BSc in Physiology and a PhD.

He published widely and his first paper, on the temperature changes in teeth produced by drilling, was on research done as an undergraduate. He was the first person to record masticatory forces in humans during natural chewing. He did this with a miniature transducer that he skilfully engineered and incorporated into a gold inlay in a molar. This was featured in a live broadcast from his laboratory in one of the early programmes in the BBC's Tomorrow's World series.
But he is best known for his work on the sensory mechanisms responsible for pain from dentine, a field to which he and his students have contributed extensively.

He also made important contributions to dental education. He believed strongly that staff involved in teaching or research in dental sciences should not be based in isolated departments in dental schools; but in larger departments in medical schools or university science faculties. He found support for this view in the 1960s from Arthur Darling, who was then Dean of the Faculty of Medicine in Bristol. As a result, Bristol created five lectureships for dentists in basic science departments in the medical school, and a chair in oral biology to oversee these posts and integrate science and clinical teaching in the dental school. Declan was appointed to that chair in 1966, and remained in the post until he retired in 1985.

The group that he formed in Bristol was very successful. At the last count, 12 of Declan's PhD students are professors and among these are past or present heads of department and deans, and the editor of an international research journal.

He had a wonderful sense of humour and sharp wit. He was very fond of practical jokes, which he often devised with his friend James Mansie at Guy's.

Declan was an accomplished silversmith. He always used traditional techniques and hand-tools, and was commissioned to make many pieces as gifts or presentations for individuals and organisations; all with his DJA hallmark, of which he was very proud. He wrote two books on silversmithing. Further details of his work as a silversmith can be found online at http://www.bristoldentalalumni.co.uk/.../ Mouthpiece-Special-Root-76-Edition.

His wife, Joy, predeceased him, as did two of their seven children.

Declan Anderson is pictured at the unveiling of a sign he made with gilded lettering on slate at the time of his retirement. Image reproduced with permission from the University of Bristol Library, Special Collections.(DM2165/93).

Bruce Matthews 